\begin{tabular}{c} 
Volume and Issues Obtainable at Center for Sustainability Research and Consultancy \\
Sustainable Business and Society in Emerging Economies \\
ISSN: 2708-2172 \& (E): 2708-2504 \\
Volume 3: Issue 3 September 2021 \\
CSRE \\
Journal homepage: $\underline{\text { www.publishing.globalcsrc.org/sbsee }}$ \\
\hline
\end{tabular}

\title{
Antecedents and Consequences of Green Human Resource Management in Oil and Gas Companies of Pakistan
}

*Ali Junaid Khan, Institute of Business, Management \& Administrative Sciences, The Islamia University of Bahawalpur, Pakistan

Salyha Zulfiqar Ali Shah, School of Economics, Bahauddin Zakariya University Multan, Pakistan Furrukh Bashir, School of Economics, Bahauddin Zakariya University, Multan, Pakistan

Jawad Iqbal, Institute of Business Management and Administrative Sciences (IBMAS), The Islamia University of Bahawalpur (IUB), Pakistan

*Corresponding author's email address: junaaidkhan@yahoo.com

\begin{tabular}{l}
\hline ARTICLE DETAILS \\
\hline History \\
Revised format: Aug 2021 \\
Available Online: Sep 2021 \\
\hline Keywords \\
Oil and Gas, Pakistan, Green \\
Human Resource \\
Management, Consequences \\
\hline
\end{tabular}

JEL Classification

O15, M11

\section{ABSTRACT}

Objective: The objective of this study is to look at the causes and consequences of green human resource management in Pakistani oil and gas companies.

Methodology: The data is collected from Pakistani oil and gas corporations. The reason for concentrating on this business is that it practices the most environmentally friendly labor practices of any other The PLS approach is used to evaluate the data received from 121 managers.

Findings: It has been found that top-level management support and environmental orientation are prerequisites to implementing green human resource management in this study. Second, it is also discovered that implementing green human resource management increase employee happiness, organizational commitment, and environmental performance. Because it provides new insights into green human resource management as well as a roadmap for accomplishing sustainable development goals, this study is important both theoretically and practically.

Implications: Employees play a critical role in helping companies achieve environmental sustainability because they are the backbone of organizations and a significant source of competitive advantage by implementing green human resource management practices, such as establishing environmental performance metrics, training employees and rewarding them for their environmental performance, this can be achieved.

(C) 2021 The authors, under a Creative Commons AttributionNonCommercial- 4.0

Recommended citation: Khan, A. J., Shah, S, Z, A., Bashir, F. and Iqbal, J. (2021). Antecedents and Consequences of Green Human Resource Management in Oil and Gas Companies of Pakistan. Sustainable Business and Society in Emerging Economies, 3 (3), 339-351. 


\section{Introduction}

Corporate social responsibility (CSR) demands that businesses take a more pro-active stance toward environmental management by achieving a better balance between environmental, economic, and societal performance. This growing concern has led to an increase in the adoption of environmental management systems (EMSs) by businesses, and research shows that adopting EMSs such as ISO 14001 certification will help companies reduce pollution, waste, and emissions, all of which can improve their performance (Abdel- Maksoud et al. 2016).

This has led to an increased level of awareness and focus on environmental management strategies used by businesses to improve their environmental performance among professionals as well as scholars and elected officials (Longoni et al. 2016). This is a strategy that promotes the firm to use a wide range of environmental systems while also promoting the firm's brand identity and increasing its profitability. Green HRM is one of these strategies (Nejati et al. 2017). Green HRM practices have been shown to improve firm performance in the past, but their effectiveness and potential benefits are still being debated (Longoni et al. 2016).

Stakeholders are pressuring businesses to take a more assertive stance on environmental issues by taking responsibility for their environmental implications, ensuring that future generations can also meet their needs and goals. This also applies to organizations. Enhancing environmental sustainability demands more than corporate compliance. Businesses, as well as the way products and services are supplied, must change in order to achieve environmental sustainability. Employees are the primary agents of change in terms of environmental performance improvement, and their success is important (Nejati et al., 2017). Without an ecologically conscious human resources department, green strategies and environmental management practices cannot be implemented successfully (Renwick et al., 2013). As described in the realm of human resources, sustainable human resource management (SHRM) refers to strategies that encourage and maintain environmental awareness while also attaining high performance results in environmental preservation.

While there has been a surge in green HRM studies due to the importance of green HRM in accomplishing environmental sustainability, current research on green HRM antecedent factors and how it affects organizational outcomes is still largely undefined (Dumont et al., 2017; Pham et al. 2019). With so few studies, we do not have a good grasp on what causes green HRM and what it does because of its effects. Green HRM precursors and consequences need to be better understood. Another issue is the lack of studies and analyses on how green HRM impacts employees. Due to the importance of identifying the implications of green HRM on workforce in order to create an effective system, this is essential (Ren et al., 2016).

Researchers are working to address this gap by looking into what causes Green HRM (GHRM) and to see the benefits of GHRM. A two-study design is used to look for GHRM's precursors. Next, we will see if putting in place green HRM has any positive effects. We add to the existing body of knowledge in two ways as a result of using a dual-perspective research strategy. As a first step, we establish a link between organizational environmental orientation, top management support, and green HRM that can facilitate the adoption of green HRM more than an aggressive management practice. Aside from helping advance knowledge on green HRM, our research identifies results at the organizational and individual level (i.e. job satisfaction and organizational commitment).

\section{Literature Review Antecedents of Green HRM}

\section{Top Management Support and Green HRM}

Research has linked the adoption of green practices to a variety of organizational and environmental factors (Gadenne et al. 2009; Abdel-Maksoud et al. 2016). Increased regulation, uncertainty in the environment, and consumer demand are examples of environmental variables. A company's size and 
resources are two examples of organizational characteristics (Lin and Ho 2011). There may only be a few notable outliers found in studies on green initiatives that take these factors into account (Guerci et al. 2016). In order to fill this knowledge gap, this research examines the most important organizational determinants of the adoption of green human resource management and finds that they are very important indeed. Top management support and a dedication to environmental protection are two examples.

For firms to implement environmentally friendly practices, support from the top down has been found in numerous studies (Daily and Huang 2001). Top management teams' views of environmental concerns as either opportunities or challenges influence corporate environmental strategy (Magrini and Lins 2007). This is up to the company's top executives to encourage a can-do attitude toward environmental policies. The implementation of disciplinary procedures and leadership support are crucial to the success of environmental management projects. Employee empowerment and disciplinary procedures are also critical. Environmental data should also be broadly distributed inside the organization (Zoogah 2011). In contrast to Miles and Covin's (2000) claim that top management has a significant impact on employee commitment to environmentally sound practices, Daily et al. (2007) claims that senior executives can act as change agents to help the organization implement an environmental management system (EMS).

An organizational culture that encourages change initiatives requires the backing of top executives (Daily and Huang 2001). Corporate cultures that encourage innovation, facilitate employee participation and reward good behavior are the only ways to encourage environmental concerns and practices. Because of this, we believe that encouraging green human resource management at the highest levels is advantageous.

H1: Top management support has a significant positive effect on green HRM.

\section{Environmental Orientation and Green HRM}

Environmental orientation is a commitment to the natural environment that reflects organizational actors' awareness of and adherence to ethical norms (Banerjee 2002). It can also be defined as "organizational mindset" that influences and is influenced by all company actions (Nair, 2015). Management and staff have the power to set and articulate internal values about the importance of environmental protection, as well. Instead, external environmental orientation focuses on how a corporation interacts with other parties outside its immediate surroundings (Banerjee et al. 2003) because of the existence of an environmental strategy that is clearly communicated allowing companies to understand their path towards environmental protection, according to preliminary research (Ramus and Steger 2000). It has been proved that implementing an effective EMS that combines company policies and initiatives results in enhancing environmental performance (Theyel 2000). This will assist the company in improving its environmental performance by cultivating a corporate culture that fosters a diversity of environmental values throughout the organization (Nair and Ndubisi 2015).

Environmental orientation could indeed help companies which become more environmentally conscious; it is contended that it can also help them adopt more environmentally friendly practices in human resource management. An environmental value system is fostered by environmental orientation, and employees are educated about the increased importance of environmental concerns, that can serve as a deterrent to the application of green human resource practices. For example, the degree to which employees in organizations care about environmental issues is a necessary requirement for green human resource management (Paille et al. 2014). A company's corporate culture is more likely to attract environmentally conscious employees and encourage environmentally friendly practices like green human resource management if environmental values are given top priority (Guerci et al. 2016). Environmental protection values will be adhered to if people are more dedicated to environmental preservation. To put it another way, environmental orientation encourages employees to engage in ecofriendly behaviours like green human resource management.

Hypothesis 2: Environmental orientation has a significant positive influence on green HRM. 


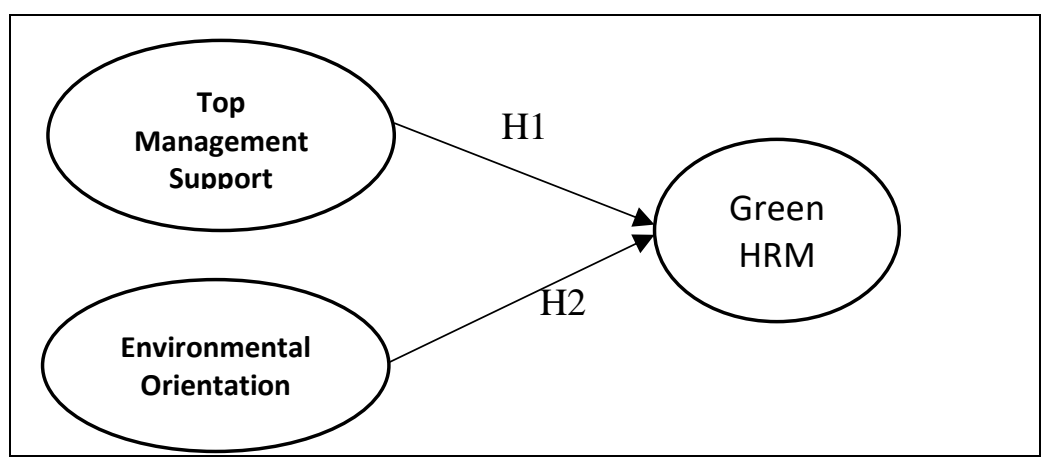

Figure 1: Antecedents

\section{Consequences of Green HRM}

\section{Green HRM and Environmental Performance}

For a company's competitive advantage to grow, it is critical to manage its human resources well (Combs et al, 2006). Additionally, the literature shows that firms are actively adopting environmentallyfriendly practices with lower costs and increased revenue streams to meet their company's environmental business objectives (O'Donohue and Torugsa, 2016). Environmental performance can be improved by employing green human resource management because it creates a solid foundation for effectively managing an organization's environmental impact. the commitment of an organization to environmental protection and stewardship demonstrated through the establishment of quantifiable operational parameters is referred to as environmental performance (Roscoe et al., 2019). Employer engagement and retention go up when green human resource management practices like environmentally friendly human resource activities are used. As a result, companies will experience a reduction in their overall carbon footprint (Sheopuri and Sheopuri, 2015). In addition, by increasing employee awareness of environmental issues, green human resource management enables organizations to improve their environmental performance (Fayyazi et al., 2015).

Human resource management is another effective way for companies to improve their environmental performance because it encourages the growth and development of 'green employees,' who are those who are hired, compensated and trained to be environmentally friendly. Employees are a company's backbone, and their pro-environmental attitudes and activities contribute to the company's overall environmental performance improvement (Kim et al., 2019). Employees are more likely to see environmental efforts and activities as shared values when they know their employers value them. There are empowering businesses to improve their environmental performance while also increasing their involvement in environmental management is a welcome side effect of this (Nejati et al., 2017). Green human resource management, according to Jabbour et al. (2008), has a significant impact on an organization's environmental performance. Firms with a strategic approach to green human resource management and personnel at all levels participating in the activities have positive environmental benefits (Yusoff et al., 2018).

Green human resource management methods foster employee green behavior and a green organizational culture. It is possible that using these measures will help organizations enhance their environmental performance (Kim et al., 2019). Studies suggest that environmentally sound human resource management is critical for long-term stability (Arda et al., 2019; Paill e et al., 2014). Vidal-Salazar et al. (2012) found a connection between environmental training and organizational learning and environmental performance. Environmental sustainability principles can only be adopted and implemented if the organization's employees are concerned about the environment (Tariq et al., 2016). Hypothesis 3: Green HRM is positively related to the organizations' environmental performance. 


\section{Green HRM and Job Satisfaction}

A company's environmental performance and employee outcomes like job satisfaction are aided by green human resource management (Chan and Hawkins, 2010). According to studies, employees' perceptions about the features of their employment have an effect on their work habits (Yusoff et al., 2018). Certain employment qualities, such as pride, involvement, and recognition, can have an effect on how people view their occupations and, consequently, their pleasure (Arnett et al., 2002). Skills diversity, task identity, task importance, autonomy and feedback are all included in the Job Characteristics Theory as being essential job traits that might cause people to feel a variety of different kinds of emotional responses. It is possible to increase an employee's intrinsic motivation by embracing different work components, which leads to increased job satisfaction and performance (Hackman and Oldham, 1976).

Corporate environmental goals can be met through green human resource management, which fosters a green environmental culture and an ecologically conscious workforce (Kim et al., 2019). According to employees, businesses should emphasize environmental protection, despite the fact that this also comes at a cost (Chan and Hawkins, 2010). This makes sense since, according to objectives of green HRM; environmental conservation should take precedence above all other factors. Chan and Hawkins (2010) discovered that when employees demonstrate environmental stewardship and try to build a healthier, more sustainable environment, they feel good about their work, which can result in job satisfaction.

Environmental visions must be established, people must be educated to communicate their environmental ideas and aspirations, environmental performance must be acknowledged, and environmentally conscious personnel must be rewarded. Green human resource management may be implemented in four steps, according to Daily and Huang (2001): manager support, training, empowerment, and rewards. Implementing eco-friendly human resource management is straightforward when done according to industry best practices. By creating a shared environmental vision and goals and providing environmental awareness training to employees, green human resource management in particular enhances skill variety, job identity, and task importance. When businesses empower and encourage employees to cooperate on environmental goals, employees develop a sense of selfdetermination. Additionally, they will be able to analyze, recognize, and reward their environmental performance, allowing them to determine the real environmental effect of their activities. Green human resource management enables employees to enhance their work behaviors by defining key job qualities.

Hypothesis 4: Green HRM has a positive relationship with employees' job satisfaction.

\section{Green HRM and Organizational Commitment}

Practices of green human resources management strengthen or establish the commitment of the organization (Jyoti, 2019). This relationship's philosophy can be summarized as a person's overall commitment to environmental stewardship. Workers who believe that the entire operation of an organization is dedicated to environmental conservation do their part by showing commitment towards the organization. One could therefore argue that practices of green human resources management help in increasing commitment of employees by boosting and enhancing organizational commitment (Yusliza et al., 2019).

Hypothesis 5: Green HRM has a positive relationship with organizational commitment 


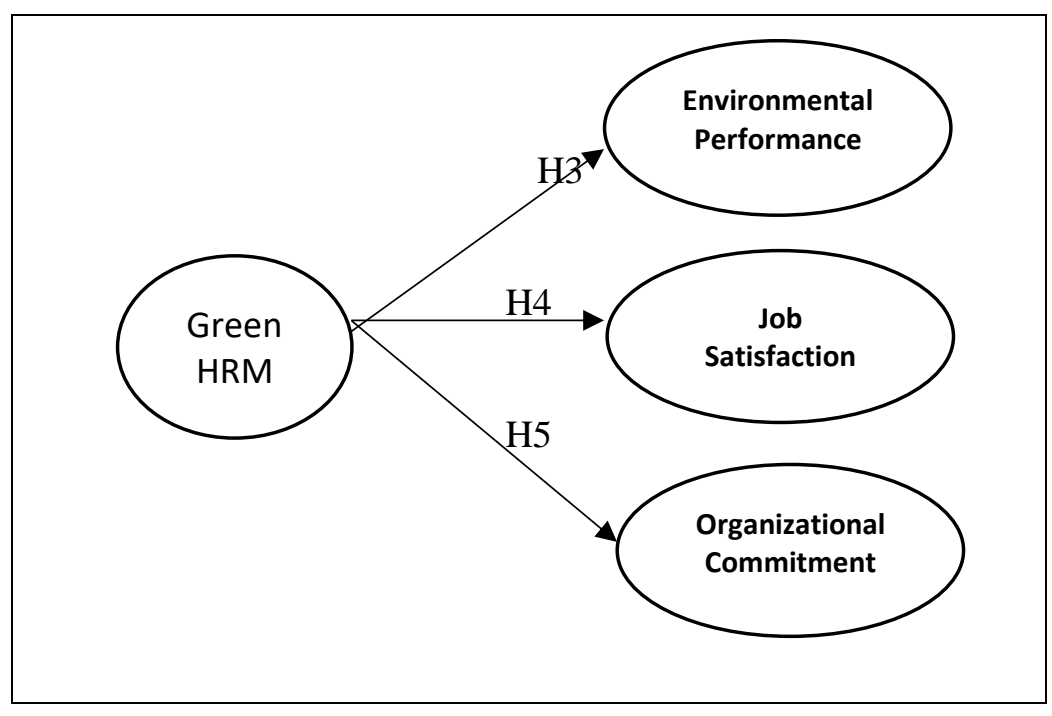

Figure 2: Consequences

\section{Methods and Data Collection}

The data is collected from Pakistani oil and gas corporations. The reason for concentrating on this business is that it practices the most environmentally friendly labor practices of any other (Wilkinson et al. 2001). Oil and gas firms are also more ecologically concerned as a result of conforming to international requirements for environmental management systems (EMS ISO 14001 certification). These systems have resulted in the establishment of policies and processes for managing a business's operations and environmental impact. Each of the participating companies employs more than 300 employees. Larger firms are more likely to implement an EMS system (Guerci et al. 2016).

This study relied on managers since they are the best sources of essential information, according to previous studies (Wagner 2013; Guerci and colleagues 2016). Drop-off and pick-up were used to deliver and collect self-administered surveys. There was a better chance of getting more responses by using this strategy (Bryman 2008). A total of 200 questionnaires were distributed and 121 were returned and included in analysis. The response rate of $60.5 \%$ in this study is considered appropriate when compared to other research in the same field (Guerci et al. 2016; O'Donohue and Torugsa 2016).

\section{Measures}

The importance of each concept has been graded using a seven-point Likert scale. The scale is built entirely on previously used and well-researched measures. The questionnaire, which was originally written in English, has been modified several times. Green HRM was quantified using the Jabbour et al. scale (2010). Respondents were asked to indicate how much of their organizations' human resource procedures are ecologically friendly. Environmental performance is quantified using a Paille et al., (2014). Organizational commitment through Allen et al. (1996) and job satisfaction is measured through the scale used by Javeria et al. (2013). Respondents were presented with a set of environmental performance indicators and questioned about their company's potential to meet them. The entire list of items can be found in Table 1 .

\section{Data Analysis}

Partial Least Squares (PLS) has been utilized to verify the research model. However, it is used in a wide range of fields, not just management research (Henseler et al. 2015). Measurement and structural models can both be evaluated in terms of their predictive validity with PLS, making it a promising technique for making predictions (Henseler et al. 2016). Because of this, multiple constructs can be analyzed at once (Hair et al. 2012). 


\section{Findings}

\section{Measurement model}

There are so many items were assessed i.e. loadings, average variance extracted, composite reliability, and Cronbach alpha to confirm the measurement model for Green HRM's antecedents and consequences. The constructs' reliability has also been established using convergent and discriminant validity tests. The item loadings, AVE, Cronbach's alpha, and CR of the constructs are listed in Table 1. All structures have item loadings that are within the suggested range of 0.7 , with the exception of a few items. It makes little difference if these items are troublesome; the fit is adequate because the constructs' AVE and CR are within an acceptable range (Hair et al., 2010). Additionally, the AVE values above the 0.5 cutoff value (Hair et al., 2010; Fornell and Larcker, 1994). According to Henseler et al. (2015), the discriminant validity of the constructs was evaluated using the HTMT (heterotrait-monotrait ratio) criterion. As shown in Tables 2 and 3, all HTMT values are less than 0.85, showing that the constructs are discriminant valid (Kline, 2011). 
Table 1: Measurement Model Analysis

\section{Variables}

Loading

\section{Antecedents \\ Top Management Support}

Our organization's top management views EMS as a critical concern.

Our organization's top management commits sufficient resources to

EMS activities.

Our organization's top management permits staff to devote time to

EMS activities.

Our organization's top management follows up on proposals for

EMS improvement.

\section{Environment Orientation}

We make a concentrated effort at our organization to ensure that

every employee understands the critical nature of environmental

preservation.

Our organisation has a clear policy statement that emphasises

environmental stewardship in all aspects of our operations.

Our organization's members place high value on environmental preservation.

Preserving the environment is a central corporate value in our organization

\section{Green HRM}

My organization recognizes employees for their environmental

stewardship.

My firm provides financial incentives to employees who

demonstrate superior environmental performance.

My organization develops precise and measurable environmental

objectives for each employee.

Environmental education is a priority in our organization.

My organization develops environmental goals for each employee.

Consequences

Job Satisfaction

In general, I am fairly content with my employment.

I enjoy my job.

I have no intention of working for another company.

Organizational Commitment

I am proud to tell others that I am an employee of this organization

I am genuinely concerned about the organization's future.

I have a little amount of loyalty to our organization.

Environmental Performance

My organization decreased trash and emissions associated with operations.

By forming relationships, my organization was able to mitigate environmental effect.

My organization's products/services have a lower environmental impact.

\section{Green HRM}

My organization recognizes employees for their environmental stewardship.

My firm provides financial incentives to employees who demonstrate superior environmental performance.

My organization develops precise and measurable environmental objectives for each employee.

Environmental education is a priority in our organization. My organization develops environmental goals for each employee.
Item

AVE Cronbach's CR

Alpha

$0.83 \quad 0.88$

0.90

0.83

0.75

0.65

0.86

0.74

0.78

0.82

0.84

0.83

0.66

0.71

0.72

0.79

0.88

0.74

0.91

0.88

0.81

0.62

$0.80 \quad 0.86$

0.92

0.93

0.89

0.77

0.82

0.94

0.90

0.84

0.73

0.82

0.83

$\begin{array}{lll}0.75 & 0.78 & 0.80\end{array}$

0.69

0.71

0.58

0.77

0.80

0.86

0.84

0.74

0.65

0.91 


\section{Structural model}

The precision and stability of the structural model were determined using the standard error and t values, and the intensity of path coefficients. (Chin 1998). Tables 4 and 5 highlight the hypothesized correlations between Green HRM antecedents and outcomes using PLS structural analysis. There is compelling evidence that senior management support is associated with effective green human resource management $(\mathrm{B}=0.053, \mathrm{P}=0.001)$. Further research demonstrated an association between environmental orientation and green human resource management $(\beta=0.049, \mathrm{P}<0.001)$, corroborating H2. Additionally, all hypotheses regarding Green HRM's impacts were confirmed. There is a significant positive link between green human resource management and environmental performance $(\beta=0.038$, $\mathrm{P}<0.001)$, job satisfaction $(\beta=0.055, \mathrm{P}<0.001)$, and organizational commitment $(\beta=0.030, \mathrm{P}<0.001)$. As a result, it is commonly agreed that all hypotheses regarding the sources and effects of Green HRM exist.

Table 2: Heterotrait-monotrait ratio (HTMT) of Antecedents

\begin{tabular}{lccc}
\hline & $\begin{array}{c}\text { Environmental } \\
\text { Orientation }\end{array}$ & Green HRM & \multicolumn{2}{c}{ Top Management } \\
Support
\end{tabular}

Table 3: Heterotrait-monotrait ratio (HTMT) of Consequences

\begin{tabular}{lcccc}
\hline & $\begin{array}{c}\text { Environmental } \\
\text { Performance }\end{array}$ & Green HRM & Job Satisfaction & $\begin{array}{c}\text { Organizational } \\
\text { Commitment }\end{array}$ \\
\hline Environmental Performance & - & - & - & - \\
\hline Green HRM & 0.84 & - & - & - \\
\hline Job Satisfaction & 0.36 & 0.81 & - & - \\
\hline Organizational Commitment & 0.77 & 0.50 & 0.70 & - \\
\hline
\end{tabular}

Table 4: Hypothesis \& Results (Antecedents)

\begin{tabular}{|c|c|c|c|}
\hline Hypothesis Pathways & Coefficient $(\beta)$ & t-Value & Decision \\
\hline Top Management Support -> Green HRM & 0.053 & $14.718 * * *$ & Supported \\
\hline Environmental Orientation -> Green HRM & 0.049 & $8.263 * * *$ & Supported \\
\hline \multicolumn{4}{|c|}{$* * *$ Significant at $p<0.001$ level, $\mathrm{t}>1.96$} \\
\hline Hypothesis Pathways & Coefficient $(\beta)$ & t-Value & Decision \\
\hline Green HRM -> Environmental Performance & 0.038 & $20.403 * * *$ & Supported \\
\hline Green HRM -> Job Satisfaction & 0.055 & $12.703 * * *$ & Supported \\
\hline Green HRM -> Organizational Commitment & 0.030 & $27.898 * * *$ & Supported \\
\hline
\end{tabular}

\section{Discussion and Conclusion}

This study adds to the body of knowledge by creating and evaluating a complete model of green human resource management's causes and effects. Green human resource management is associated with toplevel management support and an environmental perspective, which supports the first two theories. To emphasize the importance of top-level management for program execution in general and environmental management programs in particular (Steinbach et al. 2017). As previously stated, environmental orientation is critical for effective implementation of environmental management systems (Paille et al. 2014). This research shows empirically that incorporating green human resource management solutions improves environmental performance, which is in line with previous findings (Kassinis and Vafeas 2006; Guerci et al. 2016). Human resource management methods like as green hiring and green remuneration have been linked to environmental performance, according to Renwick et al. (2013).

Hypothesis 3 predicted that green human resource management will have an impact on environmental 
outcomes, and the results confirm this. A strong environmental value system can be established through green human resource management, and it educates employees about environmental issues' importance, which can serve as an enforcement mechanism to ensure that green human resource management practices are implemented and, as a result, lead to improved environmental outcomes.

The research also found a link between green human resource management and motivated employees (i.e. job satisfaction \& organizational commitment). Increasing job satisfaction and commitment has been shown to occur as a result of clarifying how green human resource management works. Considering these correlations through the prism of job characteristics theory helps explain them (Hackman and Oldham, 1976). Human resource management that prioritizes green training, develops green chances, and acknowledges green behavior promotes the three main job values of skill variety, task identity, and task importance. All of these aspects of work have an impact on people's psychological health in some way. The attitudes and views of employees about their work may have an impact on their job satisfaction and commitment to the organization. While Chan and Hawkins (2010) discovered that companies that take a proactive role in environmental problems increase the workload of employees, people maintain a strong sense of identity with their organization and a sense of purpose in their work. Employees report greater job satisfaction and organizational commitment when their workplace is ecologically friendly (Aguinis and Glavas, 2019).

\section{Practical and Managerial Implications}

The findings of this research have a wide range of practical and managerial implications. An effective strategy for improving an organization's environmental performance while also aiding the Pakistani government's Climate Action Vision is green human resource management. However, a company must lay a foundation for environmental activities before implementing green human resource management practices. In order to achieve this, the driving force behind the implementation of green initiatives should be the organization's environmental orientation. As an organization grows, its leaders need to show that environmental sustainability is a top priority by making it a part of their mission and setting business objectives around that sustainability. Middle and human resource managers can benefit from the organization's environmental culture by focusing on the green behaviors of their employees, which leads to better environmental performance.

Employees play a critical role in helping companies achieve environmental sustainability because they are the backbone of organizations and a significant source of competitive advantage by implementing green human resource management practices, such as establishing environmental performance metrics, training employees and rewarding them for their environmental performance, this can be achieved.

\section{Limitations and Direction for Future Research}

Study findings should be viewed with caution due to limitations that also indicate to future research areas. The study was meticulously designed. The study's research paradigm hinders it from studying the impact on environmental and organizational performance of top management support, environmental orientation and green human resource management at the same time. As an example, the model might be developed to look at the mediating effects of an environmentally oriented company's leadership, as well as Green Human Resources Management (HRG). It was also found that a reflective rather than formative evaluation of the Green HRM concept had been applied during the research. Studies as to whether the green HRM measurement approach is reflective or formative could be conducted in the future (Longoni et al. 2016).

\section{References}

Abdel-Maksoud, A., Kamel, H., \& Elbanna, S. (2016). Investigating relationships between stakeholders' pressure, eco-control systems and hotel performance. International Journal of Hospitality Management, 59(October), 95-104

Aguinis, H. and Glavas, A. (2019). On corporate social responsibility, sensemaking, and the search for 
meaningfulness through work. Journal of Management, 45 (3), 1057-1086.

Allen, N. J., \& Meyer, J. P. (1996). Affective, continuance, and normative commitment to the organization: An examination of construct validity. Journal of vocational behavior, 49(3), 252276.

Arda, O.A., Bayraktar, E. and Tatoglu, E. (2019). How do integrated quality and environmental management practices affect firm performance? Mediating roles of quality performance and environmental proactivity. Business Strategy and the Environment, 28 (1), 64-78.

Arnett, D.B., Laverie, D.A. and McLane, C. (2002). Using job satisfaction and pride as internalmarketing tools. Cornell Hotel and Restaurant Administration Quarterly, 43 (2), 87-96.

Banerjee, S. B. (2002). Corporate environmentalism. The construct and its measurement. Journal of Business Review, 55, 177-191.

Banerjee, S. B., Iyer, E. S., \& Kashyap, R. K. (2003). Corporate environmentalism: Antecedents and Influence of industry type. Journal of Marketing, 67, 106-122.

Bryman, A. (2008). Social research methods (Third). Oxford: Oxford University Press.

Chan, E.S. and Hawkins, R. (2010). Attitude towards EMSs in an international hotel: an exploratory case study. International Journal of Hospitality Management, 29 (4), 641-651.

Chin, W. W. (1998). The partial least squares approach for structural equation modeling. In G. A. Marcoulides (Ed.), Modern methods for business research (pp. 295-236). London: Lawrence Erlbaum Associates.

Combs, J., Liu, Y., Hall, A. and Ketchen, D. (2006). How much do high-performance work practices matter? A meta-analysis of their effects on organizational performance. Personnel Psychology, 59 (3), 501-528.

Daily, B. F., \& Huang, S. (2001). Achieving sustainability through attention to human resource factors in environmental management. International Journal of Operations and Production Management, 21, 1539-1552.

Dumont, J., Shen, J. and Deng, X. (2017). Effects of green HRM practices on employee workplace green behavior: the role of psychological green climate and employee green values. Human Resource Management, 56 (4), 613-627.

Fayyazi, M., Shahbazmoradi, S., Afshar, Z. and Shahbazmoradi, M. (2015). Investigating the barriers of the green human resource management implementation in oil industry. Management science letters, 5 (1), 101-108.

Fornell, C. and Cha, J. (1994). Partial least squares. in Bagozzi, R.P. (Ed), Advanced Methods of Marketing Research, Blackwell Business, Cambridge.

Gadenne, D. L., Kennedy, J., \& McKeiver, C. (2009). An empirical study of environmental awareness and practices in SMEs. Journal of Business Ethics, 84(1), 45-63.

Guerci, M., \& Carollo, L. (2016). A paradox view on green human resource management: Insights from the Italian context. The International Journal of Human Resource Management, 27(2), 212-238.

Hackman, J.R. and Oldham, G.R. (1976). Motivation through the design of work: test of a theory. Organizational Behavior and Human Performance, 16 (2), 250-279.

Hair, J. F., Sarstedt, M., Pieper, T. M., \& Ringle, C. M. (2012). Applications of partial least squares path modeling in management journals: A review of past practices and recommendations for future applications. Long Range Planning, 45(5-6), 320-340. https ://doi.org/10.1016/j.lrp.2012.09.008.

Hair, J., Black, W.C., Babin, B.J. and Anderson, R.E. (2010), Multivariate Data Analysis, 7th ed., Pearson Prentice Hall, New Jersey.

Henseler, J., Hubona, G., \& Ray, P. (2016). Using PLS path modeling in new technology research: Updated guidelines. Industrial Management \& Data Systems, 116(1), 2-20.

Henseler, J., Ringle, C. M., \& Sarstedt, M. (2015). A new criterion for assessing discriminant validity in variance-based structural equation modeling. Journal of the Academy of Marketing Science, 43(1), $115-135$.

Jabbour, C.J.C., Santos, F.C.A. and Nagano, M.S. (2008). Environmental management system and human resource practices: is there a link between them in four Brazilian companies?. Journal of Cleaner Production, 16 (17), 1922-1925. 
Javeria, A., Rizwan, M., Khan, A. J., Hameed, A., Neem, Q., \& Subctageen, M. (2013). Examining the Antecedents of Job Satisfaction and further its impact on Organizational Commitment. Journal of Public Administration and Governance, 3(3), 317-334.

Jyoti, K. (2019). Green HRM -People Management Commitment to Environmental Sustainability. SSRN Electronic Journal. https://doi.org/10.2139/ssrn.3323800

Kassinis, G., \& Vafeas, N. (2006). Stakeholder pressures and environmental performance. Academy of Management Journal, 49(1), 145-159.

Kim, Y.J., Kim, W.G., Choi, H.-M. and Phetvaroon, K. (2019). The effect of green human resource management on hotel employees' eco-friendly behavior and environmental performance. International Journal of Hospitality Management, 76, 83-93.

Kline, R.B. (2011), Principles and Practice of Structural Equation Modeling, Guilford Press, New York.

Lin, C. Y., \& Ho, Y. H. (2011). Determinants of green practice adoption for logistics companies in China. Journal of Business Ethics, 98(1), 67-83.

Longoni, A., Luzzini, D., \& Guerci, M. (2016). Deploying environmental management across functions: The relationship between green human resource management and green supply chain management. Journal of Business Ethics, 151, 1-15.

Magrini, A., \& Lins, L. (2007). Integration between environmental management and strategic planning in the oil and gas sector. Energy Policy, 35, 4869-4878.

Nair, S. R., \& Ndubisi, N. O. (2015). Evaluating management's environmental commitment and link with firm's environmental orientation. Journal of Management Research, 15(3), 165-178.

Nejati, M., Rabiei, S., \& Jabbour, C. J. C. (2017). Envisioning the invisible: Understanding the synergy between green human resource management and green supply chain management in manufacturing firms in Iran in light of the moderating effect of employees' resistance to change. Journal of Cleaner Production, 168, 163-172.

O'Donohue, W. and Torugsa, N. (2016). The moderating effect of 'green' HRM on the association between proactive environmental management and financial performance in small firms. The International Journal of Human Resource Management, 27 (2), 239-261.

Paille, P., Chen, Y., \& Boiral, O. (2014). The impact of human resource management on environmental performance: An employee-level study. Journal of Business Ethics, 121(3), 451-466.

Pham, N.T., Tu_ckov_a, Z. and Jabbour, C.J.C. (2019). Greening the hospitality industry: how do green human resource management practices influence organizational citizenship behavior in hotels? A mixed-methods study. Tourism Management, 72, 386-399.

Ramus, C. A., \& Steger, U. (2000). The roles of supervisory support behaviors and environmental policy in employee "ecoinitiatives" at leading-edge European companies. Academy of Management Journal, 43, 605-626.

Renwick, D. W., Redman, T., \& Maguire, S. (2013). Green human resource management: A review and research agenda. International Journal of Management Reviews, 15(1), 1-14.

Roscoe, S., Subramanian, N., Jabbour, C.J. and Chong, T. (2019). Green human resource management and the enablers of green organisational culture: enhancing a firm's environmental performance for sustainable development. Business Strategy and the Environment, 28 (5), 737-749.

Sheopuri, A. and Sheopuri, A. (2015). Green HR practices in the changing workplace. Business Dimensions, 2 (1), 13-26.

Steinbach, A. L., Holcomb, T. R., Holmes, R. M., Devers, C. E., \& Cannella, A. A. (2017). Top management team incentive heterogeneity, strategic investment behavior, and performance: A contingency theory of incentive alignment. Strategic Management Journal, 38, 1701-1720.

Tariq, S., Jan, F.A. and Ahmad, M.S. (2016). Green employee empowerment: a systematic literature review on state-of-art in green human resource management. Quality and Quantity, 50 (1), 237269.

Theyel, G. (2000). Management practices for environmental innovation and performance. International Journal of Operations and Production Management, 20(2), 249-266.

Vidal-Salazar, M.D., Cord_on-Pozo, E. and Ferr_on-Vilchez, V. (2012). Human resource management and developing proactive environmental strategies: the influence of environmental training and 
organizational learning. Human Resource Management, 51 (6), 905-934.

Wagner, M. (2013). 'Green' human resource benefits: Do they matter as determinants of environmental management system implementation? Journal of Business Ethics, 114(3), 443-456.

Wilkinson, A., Hill, M., \& Gollan, P. (2001). The sustainability debate. International Journal of Operations and Production Management, 12(12), 1492-1502.

Yong, J. Y., Yusliza, M. Y., Ramayah, T., \& Fawehinmi, O. (2019). Nexus between green intellectual capital and green human resource management. Journal of cleaner production, 215, 364-374.

Yusoff, Y.M., Nejati, M., Kee, D.M.H. and Amran, A. (2018). Linking green human resource management practices to environmental performance in hotel industry. Global Business Review, 21 (3), 1-18, doi: 10.1177/0972150918779294.

Zoogah, D. (2011). The dynamics of Green HRM behaviors: A cognitive social information processing approach. Zeitschrift fur Personal for schung, 25, 117-139. 